\title{
On the nature of extra-framework aluminum species and improved catalytic properties in steamed zeolites
}

Authors: Konstantin Khivantsev, ${ }^{1} \dagger^{*}$ Nicholas R. Jaegers, ${ }^{1} \dagger^{*}$ Libor Kovarik, ${ }^{1} \dagger^{*}$ Miroslaw A. Derewinski, ${ }^{1,2}$ Ja-Hun $\mathrm{Kwak}^{3 *}$ and Janos Szanyi ${ }^{1 *}$

\section{Affiliations:}

${ }^{1}$ Institute for Integrated Catalysis, Pacific Northwest National Laboratory, Richland, WA 99352 , USA.

${ }^{2}$ Jerzy Haber Institute of Catalysis and Surface Chemistry, Polish Academy of Sciences, Krakow 30-239, Poland

${ }^{3}$ Ulsan National Institute of Science and Technology (UNIST), South Korea.

* Correspondence to: K.K. Konstantin.Khivantsev@pnnl.gov . NRJ: NJaegers@gmail.com LK: Libor.Kovarik@pnnl.gov J.-H. K. E-mail: jhkwak@unist.ac.kr .J.Sz. E-mail:

Janos.Szanyi@pnnl.gov;

$\dagger$ These authors contributed equally to the manuscript

Abstract: Steamed zeolites have improved catalytic properties for hydrocarbon activation (alkane cracking reaction as well as alkane dehydrogenation). The nature of this practically important phenomenon has remained a mystery for the last six decades and was speculated to be related to increased Bronsted acidity during dealumination. We now prove that during steaming aluminum oxide clusters evolve (due to hydrolysis of $\mathrm{Al}$ out of framework positions with the following clustering) in the zeolitic micropores with properties very similar to (nano)facets of hydroxylated transition-alumina surfaces. Bronsted acidity of zeolite does not increase and the total number of Bronsted acid sites decreases during steaming. $\mathrm{O}_{5} \mathrm{Al}(\mathrm{VI})-\mathrm{OH}$ surface sites of alumina clusters dehydroxylate at elevated temperatures to form penta-coordinate $\mathrm{Al}_{1} \mathrm{O}_{5}$ sites that are capable of initiating alkane cracking by breaking the first $\mathrm{C}-\mathrm{H}$ bond very effectively, with the following reaction steps catalyzed by nearby zeolitic Bronsted acid sites. This explains the underlying reason behind the improved alkane cracking and alkane dehydrogenation activity of steamed zeolites: heterolytic $\mathrm{C}-\mathrm{H}$ bond breaking occurs on penta $\mathrm{Al}(\mathrm{V}){ }_{1} \mathrm{O}_{5}$ sites of aluminum oxide clusters confined in zeolitic pores. Furthermore, slightly decreased number of adjacent Al framework sites (due to Al dislodgement from the framework) decreases the coking activity, prolonging catalyst lifetime. Our findings explain the origin of enhanced activity of steamed zeolites at the molecular level and provide the missing understanding of the nature of extra-framework Al species formed in steamed/dealuminated zeolites. Furthermore, our findings suggest that similar $\mathrm{La}_{2} \mathrm{O}_{3}$ clusters exist for La-containing zeolites and the origin of their cracking activity promotion should be similar.

Zeolites are arguably the most important industrial materials employed in petroleum refining and cracking [1-9]. They are crystalline and microporous solids composed of tetrahedral $\mathrm{SiO}_{4}$ and Si$\mathrm{OH}-\mathrm{Al}$ units, with ordered arrays of micropores/microcavities: alkane transformations into more 
valuable chemicals take place in zeolitic pores at high temperatures $400-650{ }^{\circ} \mathrm{C}$. Together with transition aluminas, zeolites are mass-produced industrially, millions of tons every year [1-9]. For hydrocarbon cracking, it is known that mild steaming zeolites at elevated temperatures in the presence of water steam significantly improves their cracking activity and prolongs their lifetime [1-9]. This phenomenon has remained a mystery for the last six decades. It is generally known that steaming generates extra-framework $\mathrm{Al}$ (EFAL) species whose nature is not known, and it is often speculated that because of generation of EFAL species Bronsted acidity of zeolites somehow increases contributing to increased protolytic cracking activity [10]. Despite that, comprehensive reviews of the literature conclude that no convincing evidence exists of increased Bronsted acidity after mild hydrothermal treatment [11].

Previously, we solved a century-old old mystery of gamma-alumina surface properties and surface $\mathrm{OH}$ group assignments [12] on the surface of transition (gamma) alumina. More specifically, we found that the $\mathrm{OH}$ bands $\sim 3,770-3,780$ belong to amphoteric $\mathrm{O}_{5} \mathrm{Al}(\mathrm{VI})-\mathrm{OH}$ sites associated with most stable (100) facets and (100) nano-segments of restructured (110) surfaces [ (110) surfaces 15 of gamma-alumina restructure into (100) and (111) nano-segments; as such, although macroscopically defined (110) surface exists, its atomic-level view in fact shows that it is completely broken into (100) and (110) nano-segments, due to higher thermodynamic stability of (100) and (111) facets; this holds true for nanosized commercial high-surface area (up $200 \mathrm{~m}^{2} / \mathrm{g}$ ) SBA-200 gamma-alumina as well as larger and well-defined rhombus-platelet gamma-alumina crystals; Figs. S1,S2].

As we showed [12], the $\mathrm{OH}$ bands between 3,720-3,740 $\mathrm{cm}^{-1}$ belong to tetrahedral $\mathrm{O}_{3} \mathrm{Al}-\mathrm{OH}$ sites. Bands below 3,690 $\mathrm{cm}^{-1}$ belong to weakly acidic doubly and triply-bridging $\mathrm{OH}$ groups [Al-OH$\mathrm{Al}$ ] of gamma-alumina [12]. We also determined that alcohol dehydration catalytic activity stems from the presence of $\mathrm{O}_{5} \mathrm{Al}(\mathrm{VI})-\mathrm{OH}$ sites [12]. Upon thermal dehydroxylation, $\mathrm{O}_{5} \mathrm{Al}-\mathrm{OH}$ sites 25 transform into coordinatively unsaturated $\mathrm{O}_{5} \mathrm{Al}$ sites that can coordinate $\mathrm{N}_{2}$ and $\mathrm{CO}$.

This new understanding allows us to finally determine the nature of extra-framework Al species formed in zeolites which has not been possible before. More specifically, commonly for all zeolites H-SSZ-13, H-ZSM-5 and H-BEA zeolites upon mild steaming all produce the following signatures of extra-framework species: bands in the $-\mathrm{OH}$ stretching region at $\sim 3,770-3,780 \mathrm{~cm}^{-1}$, bands in the $30 \sim 3,660-3,640 \mathrm{~cm}^{-1}$ (Fig. S3). The 3,770-3,780 $\mathrm{cm}^{-1}$ band is often ignored because it is somewhat less intense and present as a tail on Si-OH groups [13]. The comparison between the signatures of 
$\mathrm{OH}$ groups on the surface of gamma-alumina and mildly steamed zeolites is striking and immediately suggests that the EFAL species formed in zeolites have very similar $\mathrm{OH}$ bands as transition-alumina surfaces

Fig. 1).
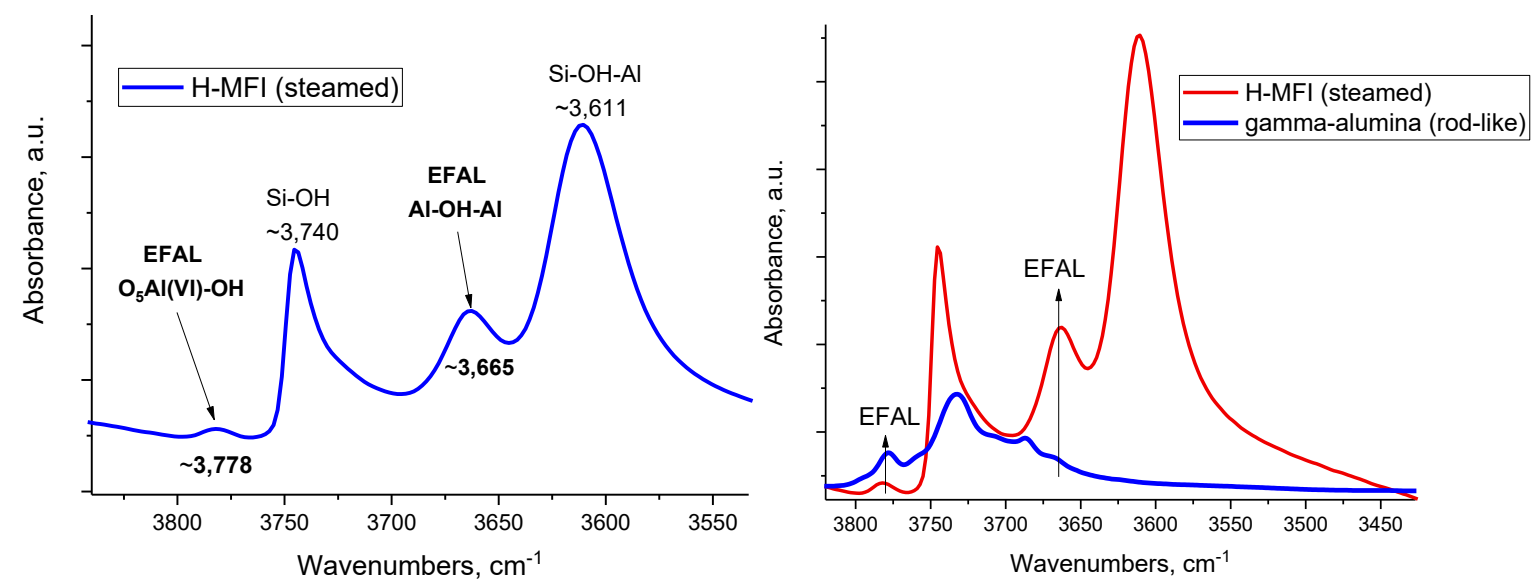

Figure 1. A. FTIR spectrum of the $\mathrm{OH}$ region of steamed H-MFI sample. B. FTIR spectrum comparison of the OH regions of steamed H-MFI and rod-like gamma-alumina sample.

$\mathrm{O}_{3} \mathrm{Al}-\mathrm{OH}$ bands $(\sim 3,720-3,740)$ are obscured by the intense $\mathrm{O}_{3} \mathrm{Si}-\mathrm{OH}$ band of zeolite.

We now prove that EFAL species in zeolite are in fact aluminum oxide clusters (formed in zeolite upon steaming) and they have similar surface properties as typical nano-segmented aluminum, oxide surfaces. As we heat the steamed H-MFI sample above $\sim 400{ }^{\circ} \mathrm{C}$, the $\sim 3,780 \mathrm{~cm}^{-1} \mathrm{OH}$ band goes down (Fig. 2).
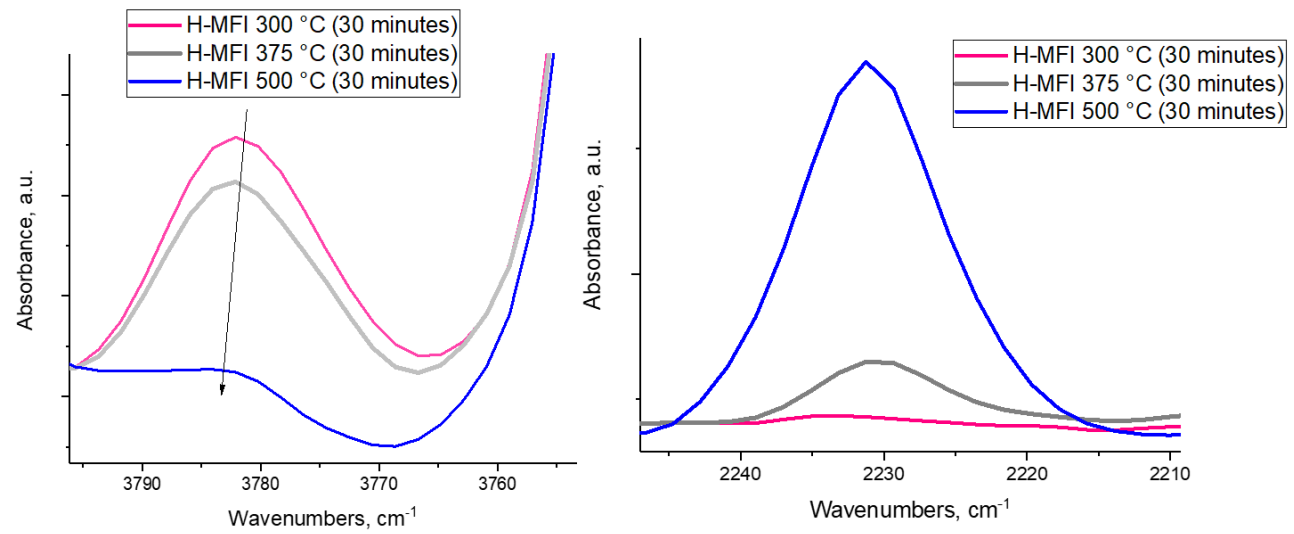

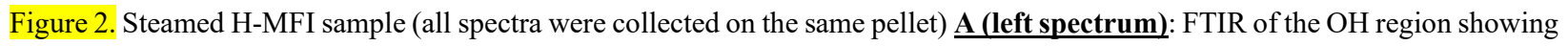
the diminishing of the $\sim 3,780 \mathrm{~cm}^{-1}$ band with temperature (spectra were recorded at room temperature). B (right spectrum): FTIR final spectra collected after introducing a total 1 Torr of CO (total pressure; room temperature) on the steamed H-MFI sample after each thermal treatment. How exactly the $\mathrm{Al}(\mathrm{V})-\mathrm{CO}$ spectra develop sequentially during in-situ $\mathrm{N}_{2}$ and $\mathrm{CO}$ adsorption is shown in Figure 4. 

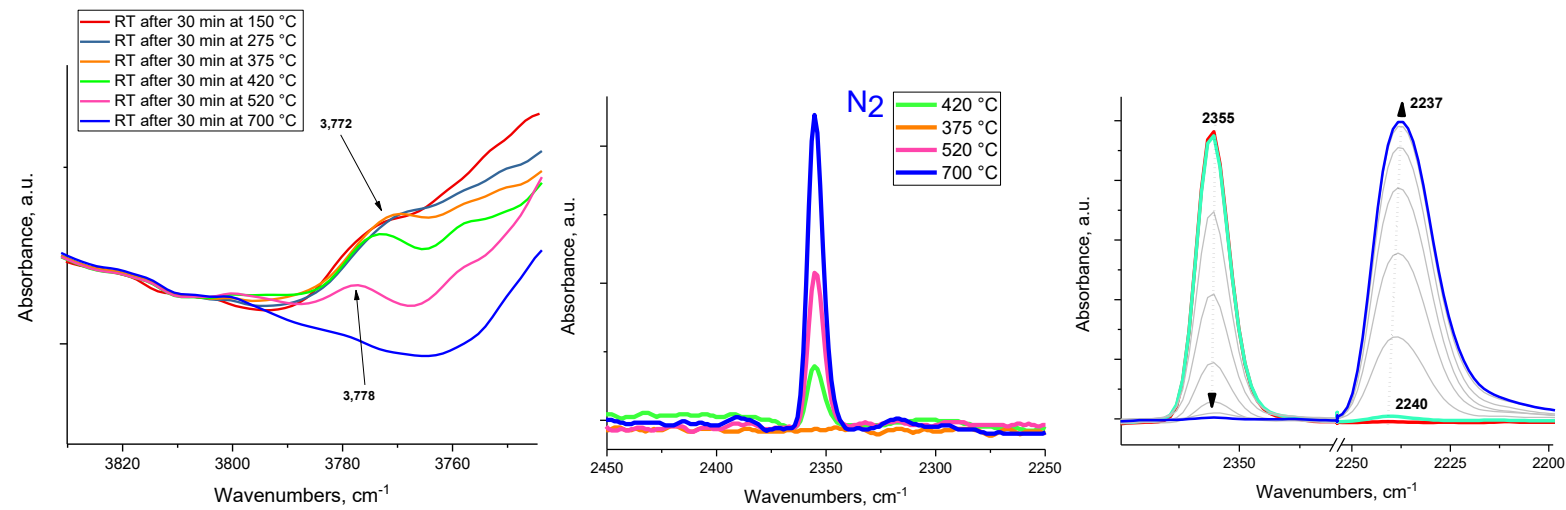

Figure 3. Rhombus-platelet gamma-alumina sample $\underline{\text { A (left spectrum) }}$ FTIR of the OH region showing the diminishing of the $\sim 3,780 \mathrm{~cm}^{-1}$ band with temperature (spectra were recorded at room temperature after each treatment). B (middle spectrum): FTIR spectra collected after introducing a total 5 Torr of nitrogen (total pressure; room temperature) on the alumina sample after each thermal treatment: evolution of the N-N stretching band is due to $\mathrm{N}_{2}$ adsorption on $\mathrm{Al}_{1} \mathrm{O}_{5}$ dehydroxylated sites (it occurs only when

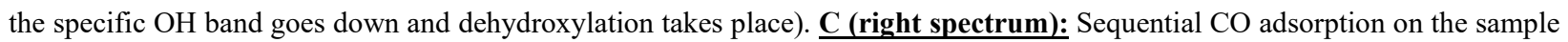
containing $\mathrm{O}_{5} \mathrm{Al}-\mathrm{N}_{2}$ complex: this establishes that $\mathrm{CO}$ displaces $\mathrm{N}_{2}$ as a coordination site in $\mathrm{O}_{5} \mathrm{Al}-\mathrm{CO}$ complex (this complex has $\mathrm{CO}$ stretch around $\sim 2,240-2,236 \mathrm{~cm}^{-1}$, similarly to the surface $\mathrm{Al}_{1} \mathrm{O}_{5}$ sites of dehydroxylated $\mathrm{Al}_{2} \mathrm{O}_{3}$ clusters in zeolites. Please note that the spectra of dehydroxylation for SBA-200 alumina sample and rod-like alumina sample are shown in Figs. S4.

Simultaneously, coordinatively unsaturated penta Al site is produced - we probe it with $\mathrm{CO}$ adsorption using Infra-Red spectroscopy. CO adsorption on the steamed (and not thermally dehydroxylated after steaming) ZSM-5 sample (where $3,780 \mathrm{~cm}^{-1}$ band is not diminished) does not lead to significant $\mathrm{CO}$ or $\mathrm{N}_{2}$ adsorption (Fig. 2). Exactly the same phenomenon is observed for various alumina samples (Fig. 3, Fig. S4): as 3,778 $\mathrm{cm}^{-1}$ band goes down (note that the location of this band is very close both for alumina (100) segments and steamed zeolite), the $\sim 2,233-2,236$ $\mathrm{cm}^{-1}$ band develops after $\mathrm{CO}$ adsorption (Fig. 2). This band is in essentially the same position as the one seen for transition alumina surfaces. Moreover, it grows in a similar fashion both for dehydroxylated alumina surfaces and dehydroxylated zeolite (Fig. 4).

Also, note that $\mathrm{N}_{2}$ adsorption on dehydroxylated $\mathrm{Al}_{2} \mathrm{O}_{3}$ clusters in zeolites also produces the N-N stretch at $\sim 2,353 \mathrm{~cm}^{-1}$ at room temperature analogously to $\mathrm{N}_{2}$ adsorption on transition-alumina surface $\sim 2,256 \mathrm{~cm}^{-1}$ band.

The more Al-OH site is dehydroxylated, the more intense the band of Al-CO complex at 2,239 $\mathrm{cm}^{-1}$ [12], which is identical to gamma-alumina. Thus, we establish equivalency between hydroxylated EFAL species and hydroxylated (100) alumina segments that dehydroxylate with the formation of coordinatively unsaturated $\mathrm{Al}_{1} \mathrm{O}_{5}$ sites. This is the direct evidence of the fact that the 
hydrated $\mathrm{Al}_{2} \mathrm{O}_{3}$ clusters that are formed in zeolite have similar $\mathrm{Al}-\mathrm{OH}$ sites as the ones seen on transition (gamma) alumina surface. They also dehydroxylate similarly producing coordinatively unsaturated $\mathrm{Al}_{1} \mathrm{O}_{5}$ sites with similar coordination/chemisorption properties (Fig. 4).
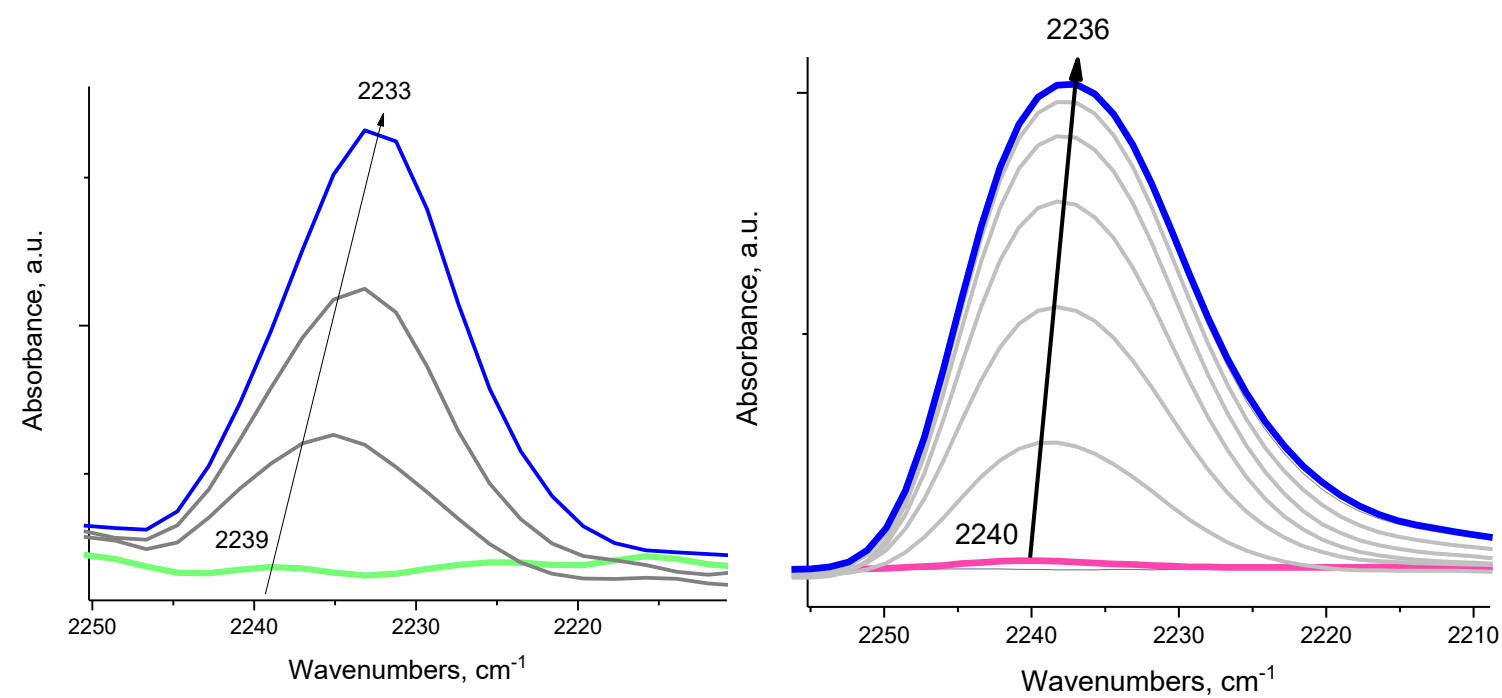

Figure 4. A (left spectrum): FTIR during sequential CO adsorption ( $\sim$ Torr) on steamed H-MFI sample after dehydroxylation at $500{ }^{\circ} \mathrm{C}$. B (right spectrum): FTIR during sequential CO adsorption ( 1Torr) on rod-like gamma-alumina sample after dehydroxylation at $500^{\circ} \mathrm{C}$.

The alumina clusters thus formed are limited in size by the zeolite dimensions $(<1 \mathrm{~nm})$ : due to this, they must consist of majorly surface sites and not bulk. Therefore, now we can explain the high fraction of penta-sites observed in steamed zeolites with NMR (Fig. S5). We previously showed that penta Al sites are located majorly on (100) segments and nano-segments of gammaalumina (Fig. S1,S2 TEM images) [12]: those segments can be as "small" as a few atoms (Figs. $\mathrm{S} 1, \mathrm{~S} 2$ ). Regular alumina samples contain majority of atoms in the bulk (tetra and octahedral Al sites): even alumina samples with relatively high surface area contain below a few percent of penta-Al sites (Fig. S6), reflected by the low contribution of the surface to the total number of Al sites. Remarkably, $\mathrm{Al}_{2} \mathrm{O}_{3}$ clusters in zeolites (due to their very small nano-sized nature) consist majorly of surface sites with the increased fraction of $\mathrm{Al}_{1} \mathrm{O}_{5}$ sites (after dehydroxylation) and $\mathrm{O}_{5} \mathrm{Al}(\mathrm{VI})-\mathrm{OH}$ sites (before dehydroxylation). Simultaneously, in steamed H-MFI Al tetra- and octa- sites broaden and develop (octa) compared with H-MFI, consistent with alumina cluster formation.

As moderate steaming removes some framework $\mathrm{Al}$ sites and produces extra-framework alumina clusters (identified herein unambiguously) enriched with surface $\mathrm{Al}_{1} \mathrm{O}_{5}$ sites (after thermal 
dehydroxylation), the propane cracking activity increases dramatically ( $\sim 6$ times) (Table 1$)$, suggesting that the presence of extra-framework alumina clusters is critical for improving cracking activity. Concomitantly, alkane dehydrogenation activity increases (Table 1).

Table 1. Propane cracking and dehydrogenation activity comparison of different samples. WHSV $\sim 20 \mathrm{hr}^{-1}$. Note that cracking produces methane and ethylene, whereas dehydrogenation produces propylene.

\begin{tabular}{|c|c|c|}
\hline Sample & $\begin{array}{c}\text { Cracking activity (methane plus } \\
\text { ethylene) } * 10^{7} \text { moles } / \mathrm{g}^{*} \mathrm{~s} ; 500^{\circ} \mathrm{C}\end{array}$ & $\begin{array}{c}\text { Dehydrogenation activity (propylene) } 10^{7} \\
\text { moles } / \mathrm{g} * \mathrm{~s} ; 500{ }^{\circ} \mathrm{C}\end{array}$ \\
\hline H-MFI & 1.4 & 1.1 \\
\hline $\begin{array}{c}\text { H-MFI steamed } \\
\text { (dehydroxylated) }\end{array}$ & 9.3 & 4.5 \\
\hline $\begin{array}{c}\text { Rhombus-platelet } \\
\text { gamma-alumina }\end{array}$ & 0.1 & 0.8 \\
\hline
\end{tabular}

Furthermore, probing Bronsted acid sites by replacing $\mathrm{H}^{+}$with $\mathrm{NO}^{+}$ions with IR active $\mathrm{N}-\mathrm{O}$ stretch $[18,19]$, shows decrease of the number of Bronsted acid sites and no increase in acid strength (Fig. 5). Therefore, despite the decrease in the Bronsted acid sites and no change in their acidity, the alkane $\mathrm{C}-\mathrm{H}$ activation activity increases dramatically due to presence of $\mathrm{Al}_{2} \mathrm{O}_{3}$ clusters.

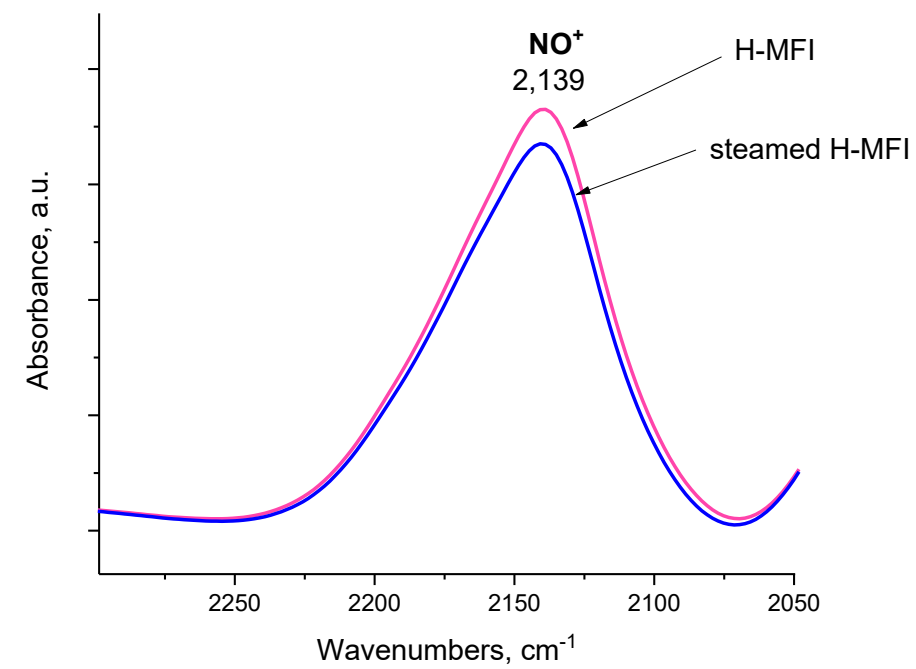

Figure 5. FTIR spectra in the N-O stretching region: comparison of parent H-MFI (containing no EFAL) and steamed H-MFI (containing EFAL). $\mathrm{NO}^{+}$was produced by $\mathrm{NO}_{2}$ adsorption ( 0.5 Torr in total). Because $\mathrm{NO}^{+}$occupies $\mathrm{H}$ sites, it is a direct measure 
of changes in Bronsted acid amount and acidity. It is clear that total number of Bronsted acid sites decreases after steaming (peak area is lower), with no evidence of increased Bronsted acidity (no shift in the $\mathrm{NO}^{+}$stretch).

Thus, it becomes clear that $\mathrm{Al}_{2} \mathrm{O}_{3}$ clusters form and due to their presence, cracking activity increases. How can alumina clusters with enriched $\mathrm{Al}_{1} \mathrm{O}_{5}$ sites help this process? We show spectroscopically (Fig. 6), that dehydroxylated $\mathrm{O}_{5} \mathrm{Al}(\mathrm{VI})-\mathrm{OH}$ sites are capable of heterolytically breaking the $\mathrm{C}-\mathrm{H}$ bond of methane (hydrocarbon with the most inert bonds and the hardest to activate) at temperatures as low as $200^{\circ} \mathrm{C}$, as well as for other saturated hydrocarbons such as octane.

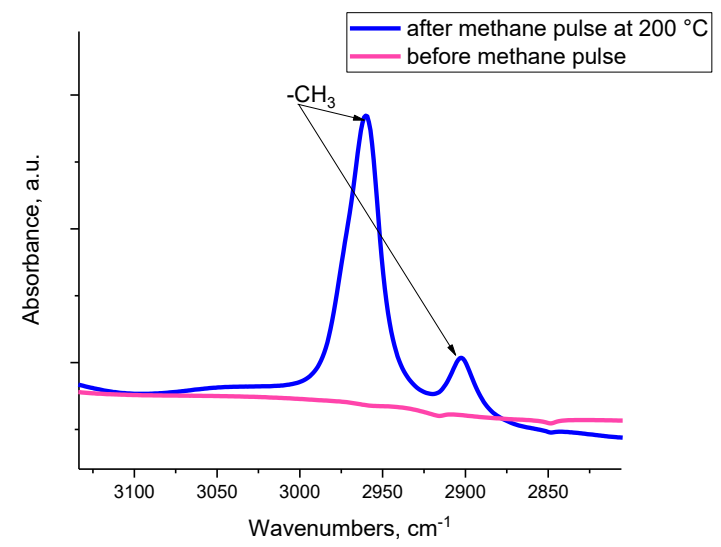

Figure 6. FTIR spectra showing the C-H stretching region of dehydroxylated gamma-alumina before and after methane pulse $(\sim 0.5$ Torr total pressure of methane) at $200^{\circ} \mathrm{C}$. The bands that grow correspond to two IR active vibrations of methyl group.

Please note, that when the $\mathrm{O}_{5} \mathrm{Al}(\mathrm{VI})-\mathrm{OH}$ sites are not dehydroxylated by thermal pre-treatment at high temperature, basically no activity is observed for activation of $\mathrm{C}-\mathrm{H}$ bonds (Fig. S7). It becomes clear that when -OH groups on $\mathrm{AlO}_{5}$ sites are present, no $\mathrm{C}-\mathrm{H}$ bond breaking occurs at temperatures when site dehydroxylation is not possible, and only when $\mathrm{Al}_{1} \mathrm{O}_{5}$ form upon thermal dehydroxylation, heterolytic $\mathrm{C}-\mathrm{H}$ bond breaking occurs with the formation of methyl fragment, identified by us spectroscopically (Fig. 6):

$\mathrm{Al}_{1} \mathrm{O}_{5}+\mathrm{CH}_{4} \rightarrow \mathrm{CH}_{3}-\mathrm{AlO}_{4}--\mathrm{OH}$ (where --OH denotes a bridging $\mathrm{OH}$ group between two $\mathrm{Al}$ atoms)

For other alkanes: $\mathrm{Al}_{1} \mathrm{O}_{5}+\mathrm{C}_{\mathrm{n}} \mathrm{H}_{2 \mathrm{n}+2} \rightarrow \mathrm{H}_{2 \mathrm{n}+1} \mathrm{C}_{\mathrm{n}}-\mathrm{AlO}_{4}--\mathrm{OH}$

25 For propane, the first step is: $\mathrm{C}_{3} \mathrm{H}_{8}+\mathrm{O}_{4} \mathrm{Al}-\mathrm{O}-\mathrm{Al} \rightarrow \mathrm{CH}_{3}-\mathrm{CH}_{2}-\mathrm{CH}_{2}-\mathrm{AlO}_{4}--\mathrm{OH}--\mathrm{Al}$. (Please note in that scheme $\mathrm{Al}_{1} \mathrm{O}_{5}$ is denoted as $\mathrm{O}_{4} \mathrm{Al}-\mathrm{O}-\mathrm{Al}$ to better show the presence of $\mathrm{Al}-\mathrm{O}-\mathrm{Al}$ bonds) 
Beta-hydride elimination on Al-propyl fragment produces propylene $\left(\mathrm{C}_{3} \mathrm{H}_{6}\right)$ and $\mathrm{Al}$ hydride species:

$\mathrm{CH}_{3}-\mathrm{CH}_{2}-\mathrm{CH}_{2}-\mathrm{AlO}_{4}--\mathrm{OH}--\mathrm{Al} \rightarrow \mathrm{C}_{3} \mathrm{H}_{6}+\mathrm{O}_{4} \mathrm{Al}(\mathrm{H})--\mathrm{OH}--\mathrm{Al}$

Hydridic hydrogen then recombines with the acidic hydrogen of the (bridging) OH group to reform the $\mathrm{Al}_{1} \mathrm{O}_{5}$ site and molecular hydrogen:

$\mathrm{O}_{4}-\mathrm{Al}(\mathrm{H})--\mathrm{OH}--\mathrm{Al} \rightarrow \mathrm{O}_{4} \mathrm{Al}-\mathrm{O}-\mathrm{Al}+\mathrm{H}_{2}$

10

Further reaction steps (leading to cracking products) then occur on Bronsted acid sites, located in the vicinity of alumina clusters: Si-O(Alkyl)-Al species form from reaction of olefin with Bronsted acid sites:

$\mathrm{C}_{3} \mathrm{H}_{6}+\mathrm{Si}-\mathrm{OH}-\mathrm{Al} \rightarrow \mathrm{Si}-\mathrm{O}\left(\mathrm{C}_{3} \mathrm{H}_{7}\right)-\mathrm{Al}$

15 This step if critical to form the alkoxy intermediate required for cracking! Once alkoxy species are formed, they can irreversibly crack on Bronsted acid sites.

This finding suggests the following rection sequence: since propane dehydrogenation reaction is reversible: $\mathrm{C}_{3} \mathrm{H}_{8} \leftarrow \rightarrow \mathrm{C}_{3} \mathrm{H}_{6}+\mathrm{H}_{2}$, the reaction is limited by the equilibrium: however, because of proximity of $\mathrm{Al}_{2} \mathrm{O}_{3}$ clusters to zeolite acid sites, once propylene forms, it can immediately participate in further irreversible reactions on Bronsted acid sites (leading to cracking products): thus, propylene is continuously removed shifting equilibrium of the reversible first reaction to the right, increasing propane conversion:

$\mathrm{C}_{3} \mathrm{H}_{8} \leftarrow \rightarrow \mathrm{H}_{2}+\mathrm{C}_{3} \mathrm{H}_{6} \rightarrow$ Zeolite-O- $\mathrm{C}_{3} \mathrm{H}_{7} \rightarrow \mathrm{C}_{1}+\mathrm{C}_{2}$ cracking products

Indeed, notably, even for regular gamma-alumina we observe that it can convert propane at 500 ${ }^{\circ} \mathrm{C}$ to propylene and hydrogen (Table 1) (please note it also can perform the microscopic reverse of this reaction: propylene hydrogenation to propane, showing that hydrogenation and dehydrogenation occur via the same intermediate). Dehydrogenation selectivity of gammaalumina is $\sim 90 \%$. Remarkably, it has $\sim 10 \%$ cracking selectivity to $\mathrm{CH}_{4}$ and $\mathrm{C}_{2} \mathrm{H}_{4}$ in ratio almost 1:1 (with minor ethane amounts due to some back-hydrogenation of ethylene to ethane). Thus, $\mathrm{Al}_{1} \mathrm{O}_{5}$ are essential for observing this activity both on gamma-alumina and zeolite. The 
cracking/dehydrogenation catalytic reactivity on zeolite is thus due to presence of $\mathrm{Al}_{2} \mathrm{O}_{3}$ clusters with coordinatively unsaturated $\mathrm{Al}_{1} \mathrm{O}_{5}$ sites next to zeolitic Bronsted acid sites.

Furthermore, based on this mechanism, the aluminum hydride species should form on $\mathrm{Al}_{2} \mathrm{O}_{3}$ clusters and Al-H species are the essential intermediates in olefin hydrogenation and alkane activation reactions. Indeed, treatment with $\mathrm{H}_{2}$ (Fig. S8) or $\mathrm{D}_{2}$ (Fig. 7) produces Al-H and Al-D stretches on gamma-alumina with H/D isotopic shift fully consistent with hydride formation. Please, note that hydrides can form on different $\mathrm{Al}-\mathrm{O}$ sites, not necessarily on $\mathrm{Al}_{1} \mathrm{O}_{5}$ site $(\mathrm{C}-\mathrm{H}$ breaking, however, seems to occur on dehydroxylated coordinatively unsaturated Al-O sites of aluminum oxide clusters):

10

$$
\mathrm{Al}-\mathrm{O}-\mathrm{Al}+\mathrm{H}_{2} \rightarrow \mathrm{H}-\mathrm{Al}-\mathrm{-OH}-\mathrm{Al}
$$

In steamed zeolites, remarkably, $\mathrm{D}_{2}$ treatment leads to the formation of hydrides with essentially the same Al-D stretching frequencies, as the ones observed on gamma-alumina, fully consistent with our findings: this is the first observation of aluminum hydride species in steamed zeolites.
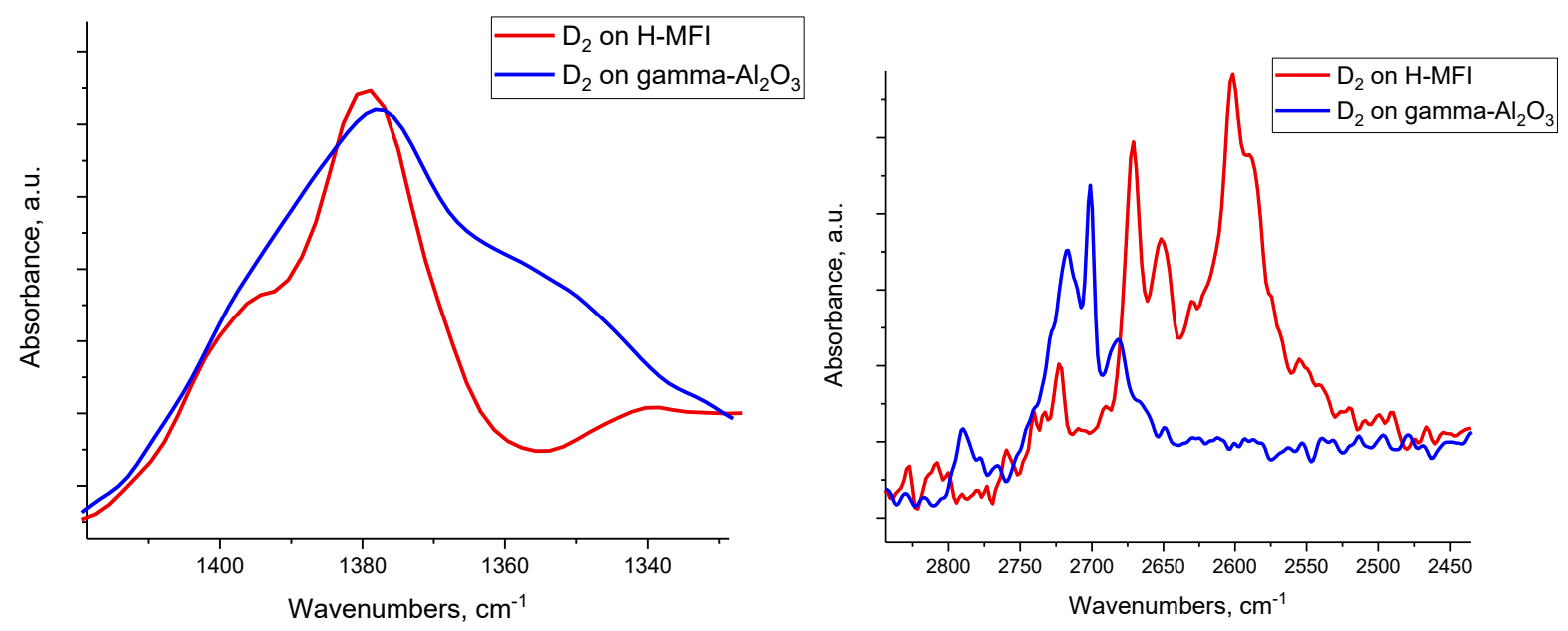

Figure 7. FTIR spectra in the Al-D (left graph) and O-D (right graph) stretching regions after $\mathrm{D}_{2}$ treatment of steamed H-MFI and gamma-alumina. Both samples were pre-treated at $500{ }^{\circ} \mathrm{C}$ prior to reaction with $\mathrm{D}_{2}$.

We also note, looking at cracking rates, that the presence of water (i.e.m OH groups) on extraframework $\mathrm{Al}_{1} \mathrm{O}_{5}$ sites is detrimental, as the activity decreases significantly (at temperatures when -OH dehydroxylation did not take place) (Table 1). This further highlights the critical role of 
dehydroxylated $\mathrm{Al}_{1} \mathrm{O}_{5}$ sites located on alumina clusters formed upon steaming. This also explains, why at lower temperatures, presence of $\mathrm{O}_{5} \mathrm{Al}(\mathrm{VI})-\mathrm{OH}$ sites with $-\mathrm{OH}$ group (dissociated water) is detrimental for alkane transformation activity (because those sites are covered by -OH groups and cannot thus provide $\mathrm{C}-\mathrm{H}$ bond breaking).

With this insight, we can now explain the previously unexplained findings in the literature that steamed zeolites can effectively catalyze $\mathrm{H}_{2}+\mathrm{D}_{2}$ exchange (to form $\mathrm{HD}$ ), as well as (benzene/hydrocarbons $+\mathrm{D}_{2}$ ) exchange to form deuterated hydrocarbons (at elevated temperatures) $[14,15]$. Previously, it has been suggested to be a zeolitic Bronsted-acid catalyzed process: our new findings suggest this view is not correct because zeolites with little EFAL have very little activity for (benzene $+\mathrm{D}_{2}$ ) exchange. Only when EFAL species are present (which we have now shown are, in fact, $\mathrm{Al}_{2} \mathrm{O}_{3}$ clusters), this process occurs. It now becomes clear how this process takes place: hydrocarbons dissociate on coordinatively unsaturated Al-O sites (Fig. 6) (this example is for benzene):

$\mathrm{C}_{6} \mathrm{H}_{6}+\mathrm{Al}-\mathrm{O}-\mathrm{Al} \rightarrow \mathrm{C}_{6} \mathrm{H}_{5}-\mathrm{Al}--\mathrm{OH}--\mathrm{Al}$

$15 \quad \mathrm{D}_{2}$ gets incorporated onto alumina surface via activation on various Al-O sites (Fig. 7):

$\mathrm{Al}-\mathrm{O}-\mathrm{Al}+\mathrm{D}_{2} \rightarrow \mathrm{D}-\mathrm{Al}--\mathrm{OD}--\mathrm{Al}$

Because bridging protons are weakly acidic [12]: they can move/"hop" between different acidic hydroxyls (in the presence of very minor moisture amounts this hopping process becomes much easier which explains some literature data suggesting that in steamed zeolites in the presence of minute moisture amounts $\mathrm{H} / \mathrm{D}$ exchange in benzene is faster [20]):

$\mathrm{H}$ in $\mathrm{OH}$ group then can exchange for $\mathrm{D}$ next to $\mathrm{Al}-\mathrm{C}_{6} \mathrm{H}_{5}$ site via the above-described protonhopping mechanism. After that, deuterated benzene evolves:

\section{$\mathrm{C}_{6} \mathrm{H}_{5}-\mathrm{Al}-\mathrm{OD}-\mathrm{-Al} \rightarrow \mathrm{C}_{6} \mathrm{H}_{5} \mathrm{D}+\mathrm{Al}-\mathrm{O}-\mathrm{Al}$}

Essentially the same process can occur on gamma-alumina surface as well (see Fig. S9 confirming $\mathrm{HD}$ formation from $\left(\mathrm{H}_{2}+\mathrm{D}_{2}\right)$ reaction on rhombus platelet gamma-alumina).

In summary, we have solved the 50-year-old mystery for the largest scale heterogeneous zeolite catalytic process: controlled steaming increases cracking activity of zeolites due to the formation 30 of alumina clusters enriched with $\mathrm{Al}(\mathrm{V})_{1} \mathrm{O}_{5}$ surface sites in zeolite micropores. These sites facilitate facile alkane $\mathrm{C}-\mathrm{H}$ bond breaking events in zeolite much more effectively than in their 
absence. Simultaneously, Bronsted acid Al-OH-Si site density decreases: this slight decrease is also beneficial because coke formation is favored by proximity of many Bronsted acid sites, and some optimal density of these Bronsted acid site exists that decreases coke formation (mesopore formation would also facilitate diffusion of those species before they form "real" coke). As long as not too much $\mathrm{Al}$ is removed from the framework and enough $\mathrm{Al}_{2} \mathrm{O}_{3}$ clusters are formed, the presence of $\mathrm{Al}_{1} \mathrm{O}_{5}$ on their surface leads to easier $\mathrm{C}-\mathrm{H}$ bond breaking events for cracking and dehydrogenation reaction. Our findings further suggest that La-promotion of cracking activity in zeolites is also related to the formation of $\mathrm{La}_{2} \mathrm{O}_{3}$ clusters in the zeolitic micropores - once dehydroxylated, these clusters possess coordinatively unsaturated La-O sites, facilitating C-H bond breaking events.

Our study also suggests that most likely no NMR "invisible" tri-coordinate Al species exist in mildly steamed zeolites (or on alumina surface) in measurable amounts. We have already shown that in some previous studies spectroscopic signatures were previously incorrectly attributed to NMR-“invisible" tricoordinate Al sites on the surface of transition aluminas - we showed that those in fact belonged to penta-Al sites [12]. The formation of tri-coordinate Al sites was additionally suggested previously for some steamed zeolites [15] on the basis of Al K-edge EXAFS modeling - the corroborating evidence for the formation of these sites was speculated to be $\mathrm{CO}$ adsorption on those " $\mathrm{Al}_{1} \mathrm{O}_{3}$ " sites producing $\mathrm{CO}$ adsorption infrared band around $\sim 2,230$ $\mathrm{cm}^{-1}$. We showed convincingly that this band belongs to penta-Al sites and is not associated with 3-coordinate Al sites. Furthermore, some recent studies took this concept even further and explained the enhanced alcohol dehydration activity in steamed zeolites by the presence of extraframework tri-coordinate Al sites: this is obviously incorrect. We herein attribute enhanced activity in alcohol dehydration for steamed zeolites to the presence of hydroxylated alumina clusters with abundant $\mathrm{O}_{5} \mathrm{Al}(\mathrm{VI})-\mathrm{OH}$ sites that are the true active sites for alcohol dehydration [12]. Furthermore, studies that claimed the presence of 3-coordinate Al sites in steamed zeolites as probed by NMR spectroscopy with $\mathrm{P}\left(\mathrm{CH}_{3}\right)_{3}$ and $\mathrm{O}=\mathrm{P}\left(\mathrm{CH}_{3}\right)_{3}$ probe molecules should be critically re-assessed: the signature ascribed to tri-coordinate $\mathrm{Al}$ sites in those studies most likely belong to strongly Lewis acidic Al(V) sites [12,17].

\section{References}


(1) H. Heinemann, "Development of Industrial Catalysis," Handbook of Heterogeneous Catalysis. Wiley-Verlag Chemie: Weinheim. 1997.

(2) Sachtler W.M.H. (2002) Catalysis from Art to Science. In: Carley A.F., Davies P.R., Hutchings G.J., Spencer M.S. (eds) Surface Chemistry and Catalysis. Fundamental and Applied Catalysis. Springer, Boston, MA

(3) W.O. Haag, R.M. Dessau, Proceedings Intern. Congress Catal. in Berlin, Germany, Vol II, p. 305. DechemaVerlag: Frankfurt am Main, Germany. 1984.

(4) D. W. Breck, US Pat., 3,130,007, 1964.

(5) N. Rahimi, R. Karimzadeh, Applied Catalysis A: General 398 (2011) 1-17

(6) R. J. Argauer, G. R. Landolt, US Pat., 3,702,886, 1972.

(7) P. B. Venuto, T. E. Habib, Fluid catalytic cracking with zeolite catalysts, Marcel Dekker, New York, 1979.

(8) J. Scherzer, Octane-Enhancing Zeolitic FCC Catalysts: Scientific and Technical Aspects, Marcel Dekker, New York, 1990

(9) D. W. Breck and E. M. Flanigen, Molecular Sieves, London, 1968, p. 47.

(10) J. Haw, Phys. Chem. Chem. Phys., 2002, 4, 5431-5441

(11) S.M. Babitz, B.A. Williams, J.T. Miller, R.Q. Snurr, W.O. Haag, H.H Kung, Applied Catalysis A: General 179 (1999) 71-86

(12) K. Khivantsev, N. R. Jaegers, J.-H. Kwak, J. Szanyi, L. Kovarik, Angew. Chem. Int. Ed. 2021, 60, 2 - 11

(13)J. Szanyi, M.T. Paffett, Microporous Materials 7 (1996) 201218

(14) Kramer, G. J.; van Santen, R. A.; Erneis, C. A.; Nowak, A. K. Nature, 1993, 363, 529-31.

(15)Kramer, G. J.; van Santen, R. A. J. Am. Chem. Soc. 1995117 1766-76.

(16)J. A. van Bokhoven, A. M. J. van der Eerden, D. C. Koningsberger, J. Am. Chem. Soc. 2003, 125, 7435-7442

(17)J.-P. Gilson, G. C. Edwards, A. W. Peters, K. Rajagopalan, R. F. Wormsbecher, T. G. Roberie, M. P. ShatlockJ. Chem. Soc., Chem. Commun., 1987 91-92

(18) Khivantsev, K., Jaegers, N.R., Kovarik, L. et al. Emiss. Control Sci. Technol. 6, 126-138 (2020).

(19) K. Hadjiivanov, Catalysis Reviews 200042 (1-2), 71-144

\section{Acknowledgments:}

The research described in paper is part of the Quickstarter Initiative at Pacific Northwest National

Laboratory. It was conducted under the Laboratory Directed Research and Development Program at PNNL, a multiprogram national laboratory operated by Battelle for the U.S. Department of Energy (DOE) under Contract DE-AC05-76RL01830. The research described in this paper was performed in the Environmental Molecular Sciences Laboratory (EMSL), a national scientific user facility sponsored by the DOE's Office of Biological and Environmental Research. This work was supported by US Department of Energy, Office of Science, Office of Basic Energy Sciences, Division of Chemical Sciences, Biosciences, and Geosciences.

Competing interests: Authors have no conflicts to eclair.

Data and materials availability: All data is available in the main text or the supplementary materials. 


\section{Supporting Information:}

\section{On the nature of extra-framework aluminum species and improved catalytic properties in steamed zeolites}

Authors: Konstantin Khivantsev, ${ }^{1} \dagger^{*}$ Nicholas R. Jaegers, ${ }^{1 *}$ Miroslaw A. Derewinski, ${ }^{1,2}$ Libor Kovarik, ${ }^{1} \uparrow$ Ja-Hun Kwak ${ }^{3 *}$ and Janos Szanyi ${ }^{1}{ }^{\dagger *}$

\section{Affiliations:}

${ }^{1}$ Institute for Integrated Catalysis, Pacific Northwest National Laboratory, Richland, WA 99352 , USA.

${ }^{2}$ Jerzy Haber Institute of Catalysis and Surface Chemistry, Polish Academy of Sciences, Krakow 30-239, Poland

${ }^{3}$ Ulsan National Institute of Science and Technology (UNIST), South Korea.

* Correspondence to: K.K. Konstantin.Khivantsev@pnnl.gov. NRJ: njaegers@gmail.com LL:

25 Libor.Kovarik@pnnl.gov J.-H. K. E-mail: jhkwak@unist.ac.kr.J.Sz. E-mail: Janos.Szanyi@pnnl.gov;

$\uparrow$ These authors contributed equally to the manuscript

\section{Materials and methods}

MFI sample in the ammonium form with $\mathrm{Si} / \mathrm{Al}$ ratio $~ 15$ was supplied by Zeolyst. First, this sample was calcined in the dry air flow at $550^{\circ} \mathrm{C}$ for 5 hours to remove ammonia. The sample was subsequently subjected to treatment with the $\sim 0.1 \mathrm{M}$ solution of ammonium hexafluorosilicate $(99.999 \%$, sigma 
aldrich) under continuous stirring for 15 minutes at $80{ }^{\circ} \mathrm{C}$. The powder was then centrifuged and washed multiple times with DI water. The zeolite cake was then dried under $\mathrm{N}_{2}$ flow in the furnace at $\sim 100{ }^{\circ} \mathrm{C}$, and subsequently calcined at $550{ }^{\circ} \mathrm{C}$ for 3 hours in the flow of dry air. This produced the HMFI sample titled "H-MFI” for our experiments.

To produce the steamed H-MFI sample (containing extra-framework Al species), H-MFI was subjected to steam treatment at $420^{\circ} \mathrm{C}$ in the flow-through quartz reactor with air flow through the water saturator for 30 minutes. The sample was cooled down in the flow of wet air to $200{ }^{\circ} \mathrm{C}$, and then held at $200{ }^{\circ} \mathrm{C}$ in the flow of dry air for 1 hour before cooling. This sample is called "steamed H-MFI".

Other H-zeolites were steamed using similar method, such as H-SSZ-13 and H-BEA (their infrared spectra are shown in Fig. S2).

Rhombus-platelet $\gamma$-alumina used was synthesized from aluminum isopropoxide via a hydrolysis method (ref 12). More specifically, approximately $10 \mathrm{~g}$ of aluminum isopropoxide was added to $\sim 50 \mathrm{~mL}$ of water with vigorous stirring at $80{ }^{\circ} \mathrm{C}$ for $1 \mathrm{~h}$. The mixture was transferred to the $125 \mathrm{~mL}$ Teflon liner of a Parr reactor and placed into an oven and kept at 200 ${ }^{\circ} \mathrm{C}$ for $24 \mathrm{~h}$. After cooling to room temperature, the powder was collected by filtration, washed with distilled water, and dried at $100^{\circ} \mathrm{C}$. The as-synthesized boehmite powder was then calcined at $800{ }^{\circ} \mathrm{C}$ for $2 \mathrm{~h}$ to convert it to rhombus-platelet $\gamma$-alumina with surface area of approximately $70 \mathrm{~m}^{2} / \mathrm{g}$.

Commercial SBA-200 $\gamma$-alumina with surface area $\sim 200 \mathrm{~m}^{2} / \mathrm{g}$ was used without additional pretreatment.

Rod-like $\gamma$-alumina (with surface area $\sim 70 \mathrm{~m}^{2} / \mathrm{g}$ ) was synthesized according to the previous method at the $\mathrm{pH} \sim 4($ ref 12$)$.

The in-situ static transmission IR experiments were conducted in a home-built cell housed in the sample compartment of a Bruker Vertex 80 spectrometer, equipped with an MCT detector and operated at $4 \mathrm{~cm}^{-1}$ resolution. The powder sample was pressed onto a tungsten mesh which, in turn, was mounted onto a copper heating assembly attached to a ceramic feedthrough. The sample could be resistively heated, and the sample temperature was monitored by a thermocouple spot welded onto the top center of the $\mathrm{W}$ grid. The cold finger on the glass bulb containing CO (99.995\%) was cooled with liquid nitrogen to eliminate any contamination originating from metal carbonyls, while $\mathrm{NO}_{2}$ (99.9\%) was cleaned with multiple freeze-pump-thaw cycles. Research-grade methane (purity 
99.995\%) was used. Octane (anhydrous, 99.99\% sigma-aldrich) was purified with multiple freezepump-thaw cycles and stored in a glass bulb. $\mathrm{D}_{2}$ was purchased from Cambridge Isotopes, it was contained in a glass bulb and purified with liquid nitrogen trap to remove moisture traces. Researchgrade $\mathrm{H}_{2}$ was used (99.995\% purity).

Microscopy analysis was performed with a FEI Titan 80-300 microscope operated at $300 \mathrm{kV}$. The instrument is equipped with a CEOS GmbH double-hexapole aberration corrector for the probe-forming lens, which allows for imaging with $0.1 \mathrm{~nm}$ resolution in scanning transmission electron microscopy mode (STEM). HAADF-STEM images were acquired with a high angle annular dark field (HAADF) detector with inner collection angle set to $52 \mathrm{mrad}$.

${ }^{27} \mathrm{Al}$ MAS NMR measurements were performed at room temperature on a Bruker $850 \mathrm{MHz}$ NMR spectrometer, operating at a magnetic field of $19.975 \mathrm{~T}$. The corresponding ${ }^{27} \mathrm{Al}$ Larmor frequency is $221.4125 \mathrm{MHz}$. A single pulse sequence comprised of a $\pi / 9$ pulse width of $0.3 \mu \mathrm{s}$, a recycle delay of $2 \mathrm{~s}$, and an acquisition time of $30 \mathrm{~ms}$ was employed to collect the free induction decays (FID). To enhance the intensity of the observed spectral features over the noise, 4,096 repetitions were employed for each FID. Each collected FID was subsequently Fourier Transformed to the frequency domain where both zero and first order phase corrections were applied. The broad spectrometer background signal was collected with a sample containing no Al species under the same conditions and subsequently subtracted from each Al spectra. The data were simulated for best fit and the intensities of each coordination environment from the simulations were taken together to provide the fractional abundance. Total intensity was normalized to the carefully measured mass of each sample used for the NMR experiment, which was typically $\sim 15 \mathrm{mg}$. All NMR data were acquired at a sample spinning rate of $18.7 \mathrm{kHz}( \pm 5$ $\mathrm{Hz}$ ) and externally referenced to $1.0 \mathrm{M}$ aqueous $\mathrm{Al}\left(\mathrm{NO}_{3}\right)_{3}(0 \mathrm{ppm})$. The samples were packed inside $3.2 \mathrm{~mm}$ pencil-type NMR rotors. The rotors were subsequently sealed and placed in vials until transported to the NMR probe.

Catalytic experiments were performed in the quartz flow-through reactor. $75 \mathrm{mg}$ of catalyst powder was loaded in the reactor and thermally pre-treated in the flow of dry air at $500{ }^{\circ} \mathrm{C}$, and then purged with dry Helium at this temperature for 30 minutes (reactions at $390{ }^{\circ} \mathrm{C}$ were also performed: in this case, the temperature was quickly ramped to the desired temperature $\left(390{ }^{\circ} \mathrm{C}\right)$ and catalytic activity was tested at this temperature). UHP 2\% Propane in He gas mixture was 
used. WHSV was $\sim 20 \mathrm{hr}^{-1}$. Products were quantified with gas chromatography with FID detector. Propane conversions were $<2 \%$. Reaction was performed at temperatures $500{ }^{\circ} \mathrm{C}$ and $400{ }^{\circ} \mathrm{C}$. 


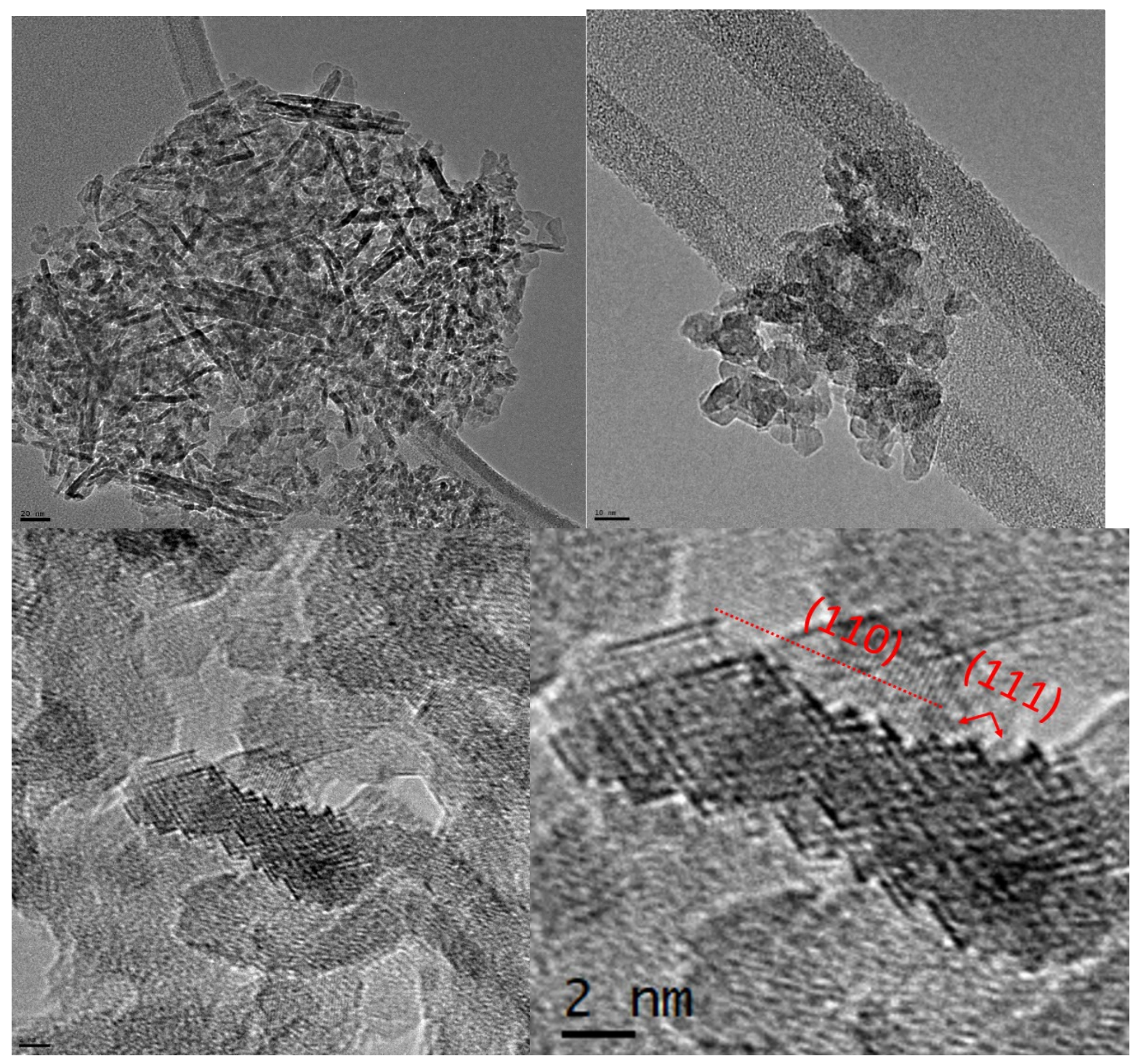

Figure S1. typical HRTEM images of high surface area $\left(\sim 200 \mathrm{~m}^{2} / \mathrm{g}\right)$ SBA-200 $\gamma$-alumina sample. It consists of abundant platelets can be easily seen (image 1) as well less common less welldefined nanocrystal shapes (image 2). Image 3 shows nanocrystal of SBA-200 with macroscopically defined (110) surface: image 4 shows magnified nanocrystal showing that (110) facet is reconstructed into (111) and (100) ridges, completely analogous to all gamma-alumina surfaces. 

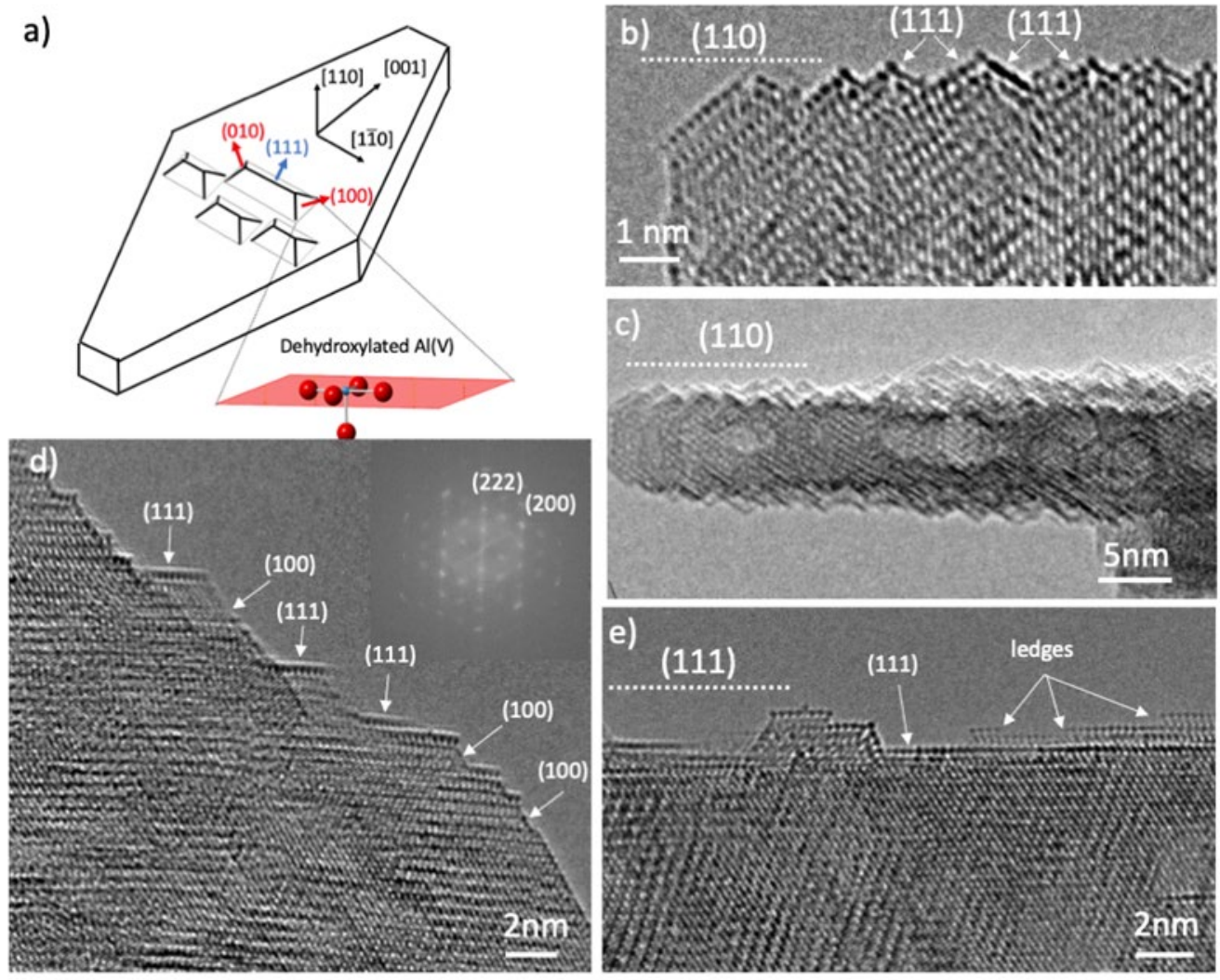

Figure S2. A). Schematic of rhombus-platelet alumina crystals showing reconstruction of (110) surface into (100 and (111) nano-segments. B)-C). Atomically resolved HRTEM image (110) surfaces of rhombus-platelet $\gamma$-alumina. The (110) surface is reconstructed into (111) and (100) facets. This is typical for all gamma-alumina samples. D). HRTEM observation of an irrational surface of $\gamma$-alumina showing that it also contains (100) and (111) nano-segments. (e) HRTEM image of (111) surface facet. 


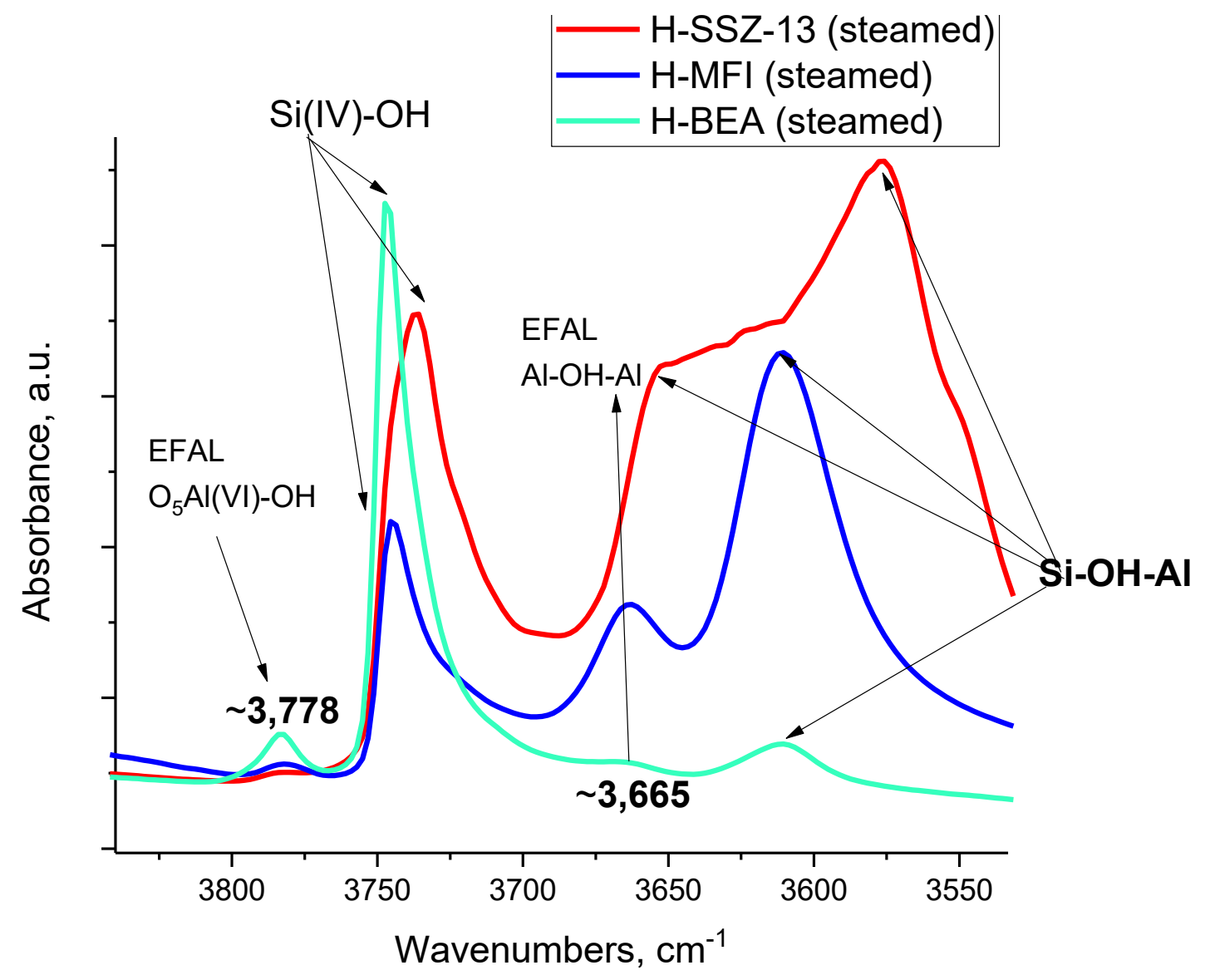

Figure S3. FTIR of the OH region of steamed H-SSZ-13, H-BEA and H-MFI samples showing similar EFAL features for all of them. 

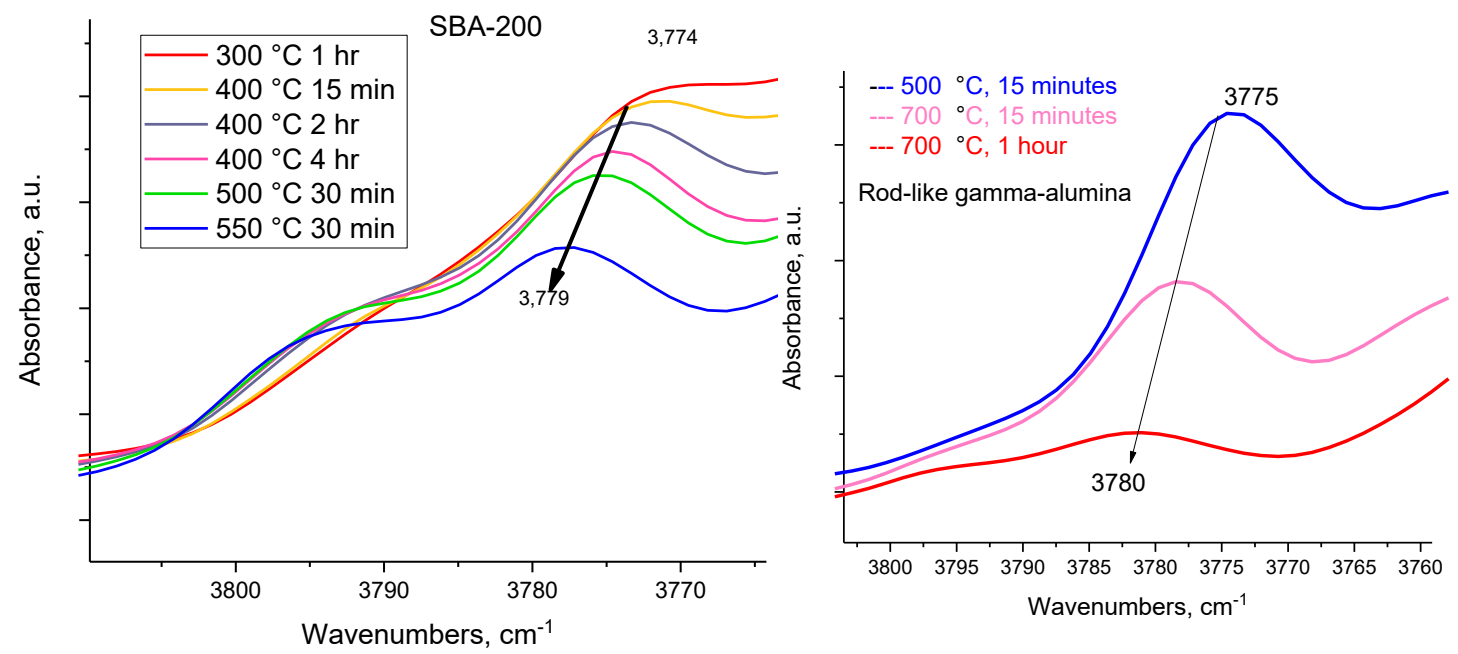

Fig. S4. FTIR of the $\mathrm{OH}$ region of SBA-200 and rod-like gamma-alumina samples during thermal treatments. Spectra were recorded at room temperature after specified thermal treatments.

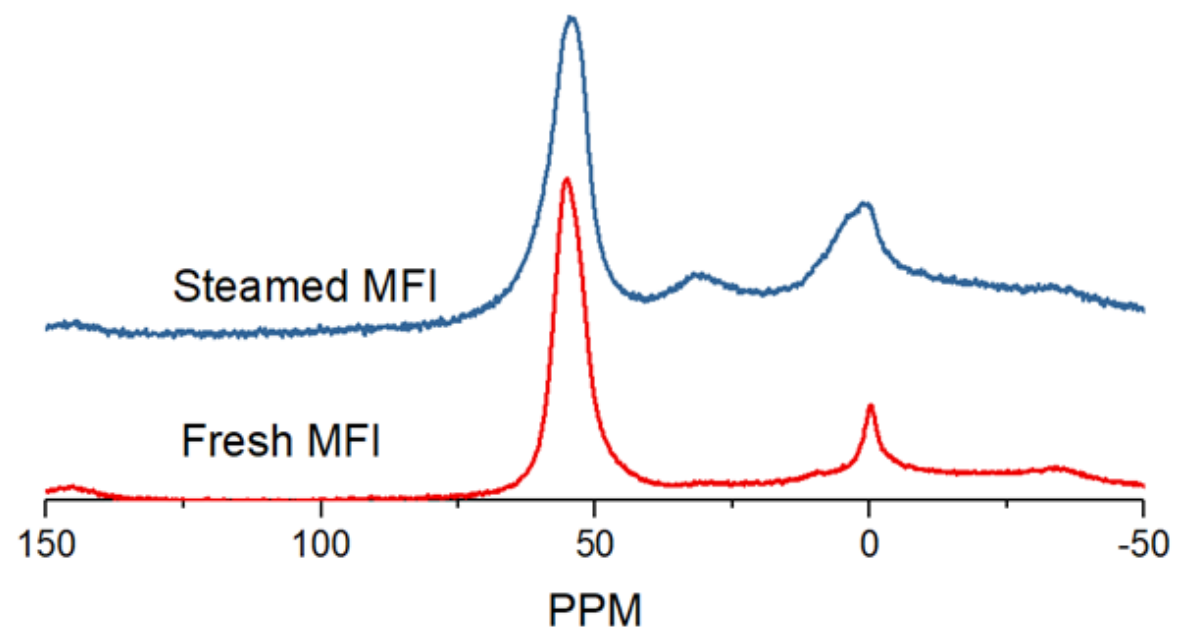

Fig. S5. Solid-state ${ }^{27} \mathrm{~A} 1 \mathrm{NMR}$ of fresh and steamed MFI samples. The band $\sim 33 \mathrm{ppm}$ corresponds to penta-coordinated $\mathrm{Al}$. 


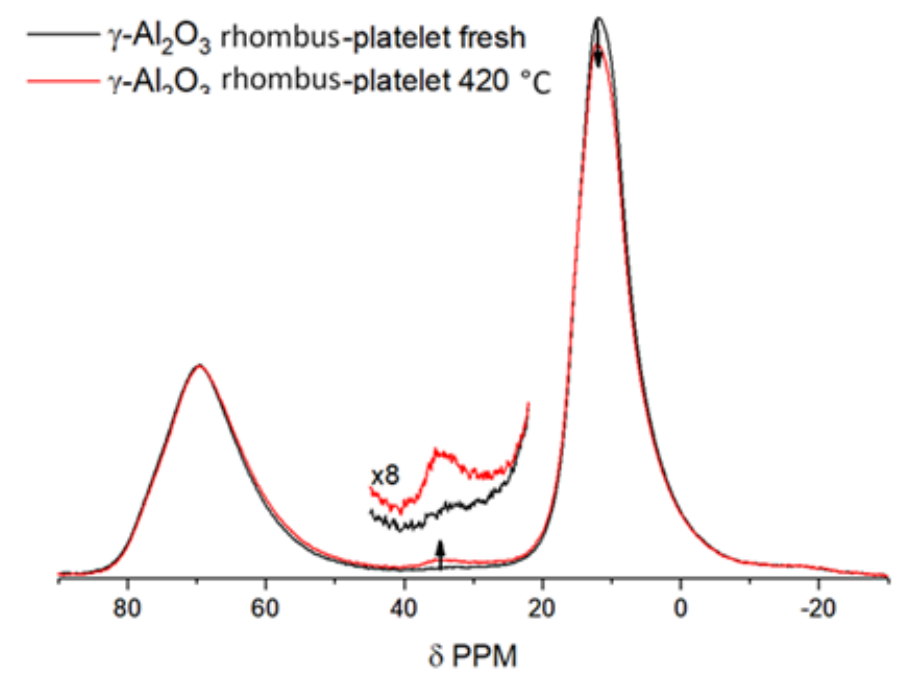

Fig. S6. Solid-state ${ }^{27}$ Al NMR fresh and dehydroxylated rhombus-platelet gamma-alumina sample $\left(\mathrm{SA} \sim 70 \mathrm{~m}^{2} / \mathrm{g}\right)$. Only tetra, penta and octa-Al sites are present. Upon dehydroxylation, surface octahedral $\mathrm{O}_{5} \mathrm{Al}(\mathrm{VI})-\mathrm{OH}$ sites dehydroxylate [12] and form penta-sites. Their small abundance is due to the fact that majority of Al remains in the bulk (tetra and octa-Al sites), and only a smaller fraction of $\mathrm{Al}$ sites resides on the surface. As the Alumina nano-particle size decreases, more and more Al surface atoms (in terms of relative surface/bulk ratio) get exposed as evidenced from Fig. S5 and discussion in the main text. 


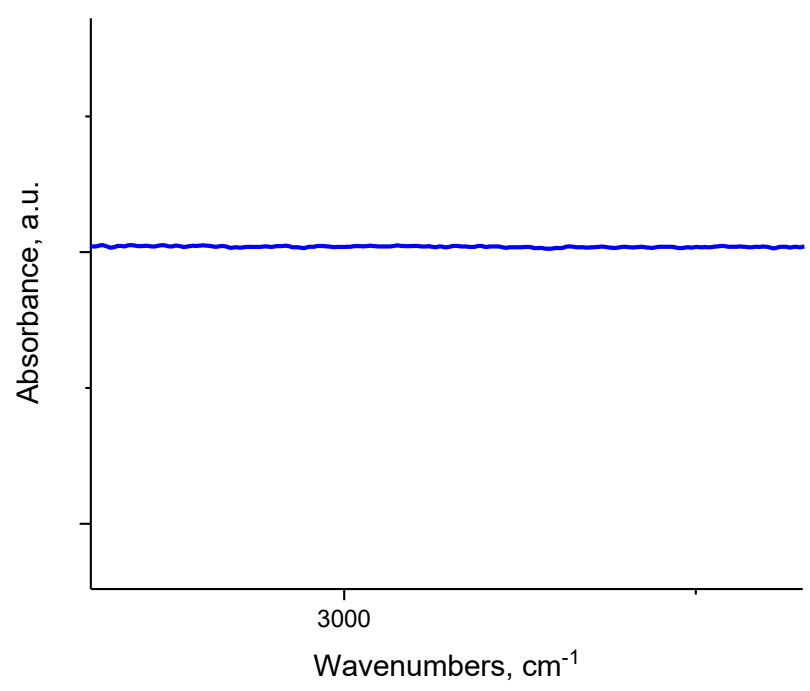

Figure S7. FTIR spectra showing the $\mathrm{C}-\mathrm{H}$ stretching region of gamma-alumina that was not treated at high temperature (the sample was heated at $300{ }^{\circ} \mathrm{C}$ under vacuum for 15 minutes, this treatment is not enough to dehydroxylate $\mathrm{O}_{5} \mathrm{Al}(\mathrm{VI})-\mathrm{OH}$ sites) before and after methane pulse at 5 $200{ }^{\circ} \mathrm{C}$. 


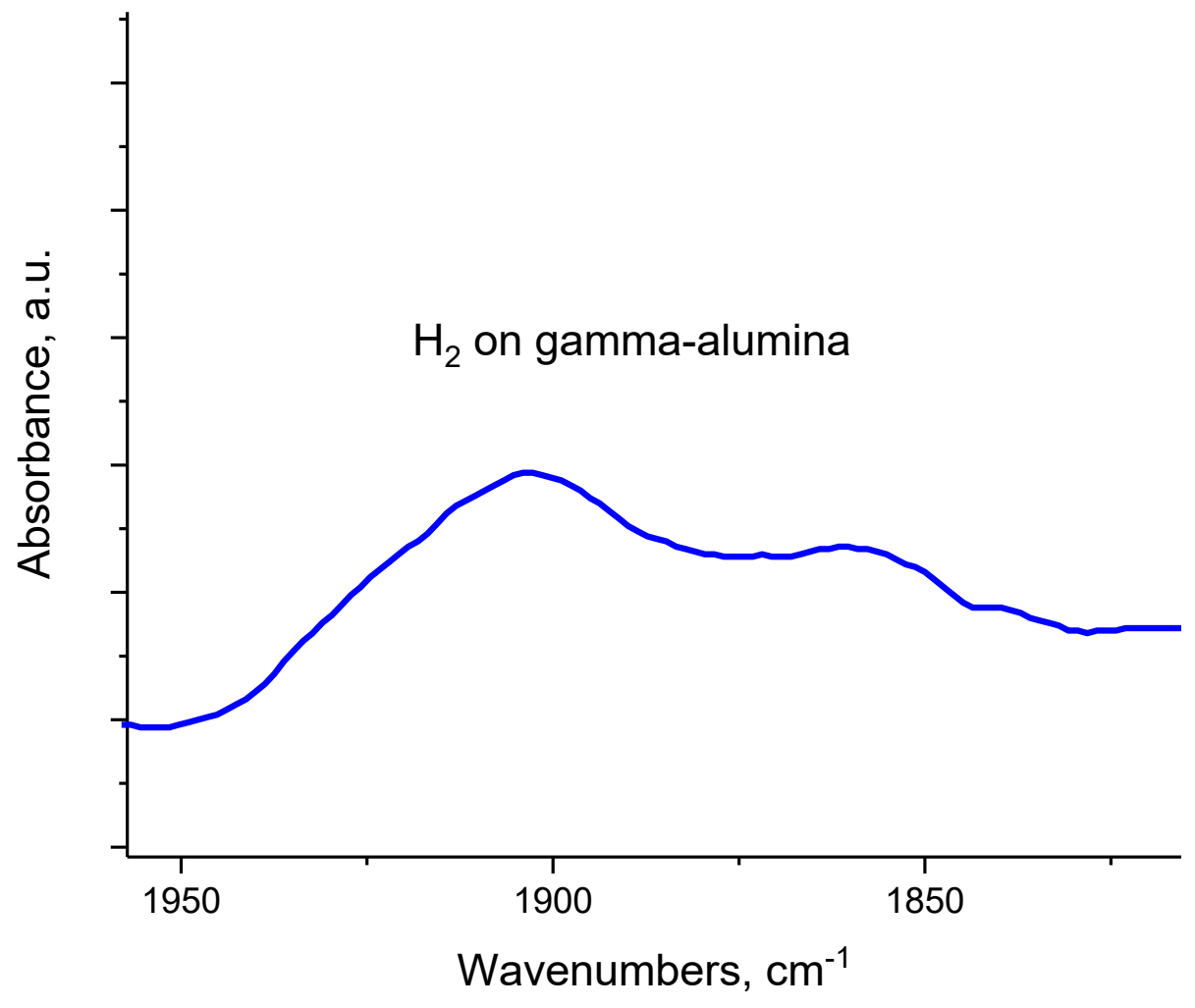

Figure S8. FTIR spectra in the Al-H stretching region after $\mathrm{H}_{2}$ treatment of gamma-alumina (treated at $500^{\circ} \mathrm{C}$ ). 


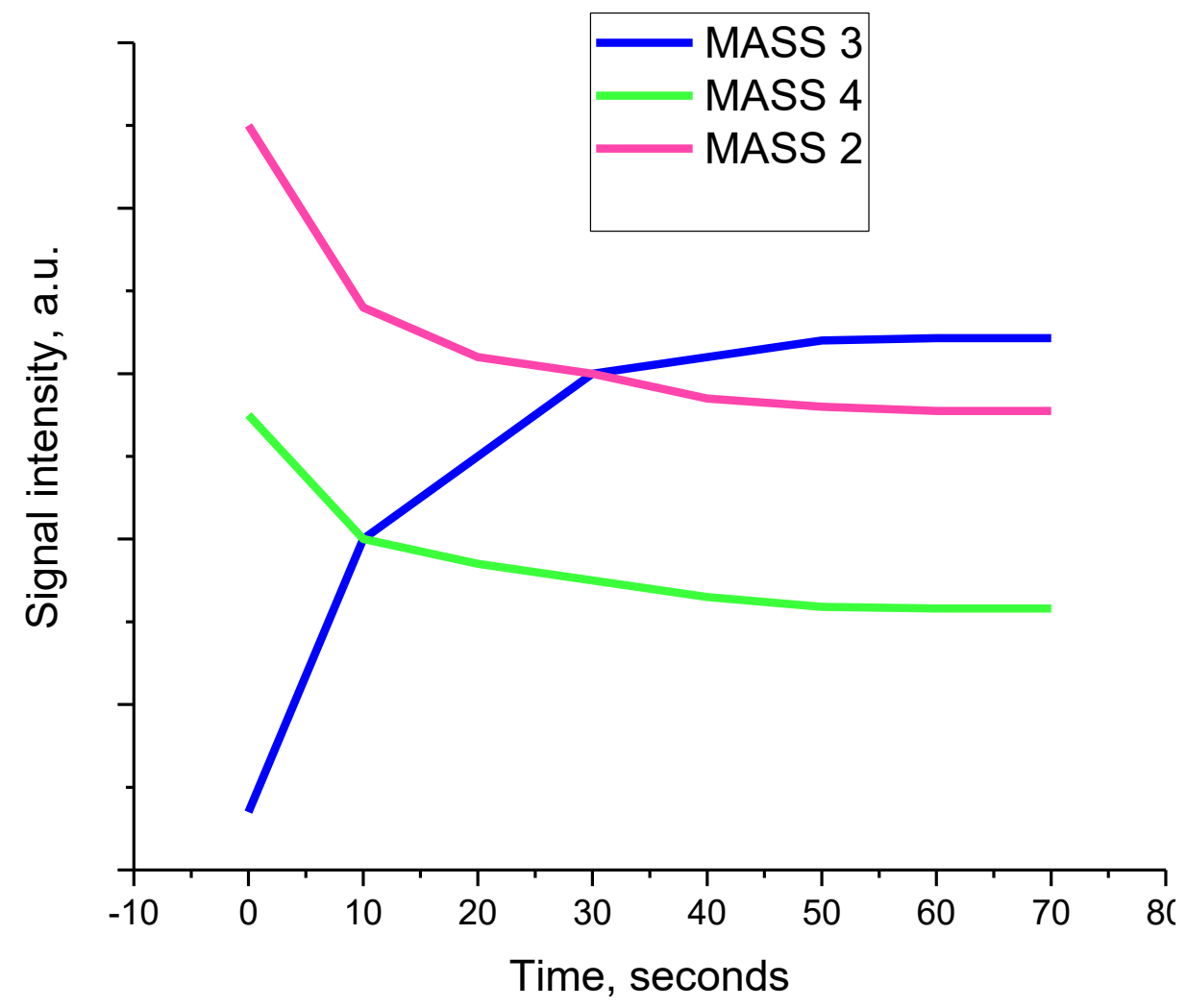

Figure $\mathrm{S} 9 . \mathrm{H}_{2}+\mathrm{D}_{2}$ reaction monitored with mass-spec in static FTIR system at temperature 100 ${ }^{\circ} \mathrm{C}$. A mixture of $\mathrm{H}_{2}+\mathrm{D}_{2}$ was pre-mixed in $~ 1.6-1.7$ volume ratio and introduced into the infrared cell with rhombus-platelet gamma-alumina sample (dehydroxylated at $500{ }^{\circ} \mathrm{C}$ ). Mass 3 corresponds to product of the reaction HD. Mass 2 corresponds to $\mathrm{H}_{2}$. Mass 4 corresponds to $\mathrm{D}_{2}$. 